\section{Food-dependent exercise-induced anaphylaxis without IgE sensitivity - A rare challenging condition}

Arq Asma Alerg Imunol. 2021;5(4):435-6.

http://dx.doi.org/10.5935/2526-5393.20210065

\section{Dear Editor,}

Exercise-induced anaphylaxis displays 4 different categories (Table 1). ${ }^{1}$ The modality food-dependence without $\operatorname{lgE}$ sensitivity is rare and not documented extensively in the literature. ${ }^{2,3}$ We therefore are herein presenting 3 illustrative cases.

Table 1

Categories of exercise-induced anaphylaxis

- Primary food-independent

- Food-dependence with $\lg E$

- Food-dependence without IgE

- With drug-dependence

\section{Case 1}

A 31-years-old caucasian male with atopic dermatitis and allergic rhinitis refers recurrent anaphylaxis since the age of 4 years old. After eating wheat containing foods, such as pizza, sandwiches and cakes, and exercising afterwards, he always has pruritus, generalized urticaria, angioedema, diarrhea, and frequent fainting episodes. He is able to exercise normally if not eating wheat products previously and he can eat wheat containing foods if not exercising afterwards. The combination of both factors triggers the referred symptoms. The patient has a positive family history for atopy. Laboratory evaluation showed 541 eosinophils $/ \mathrm{mm}^{3}(8,2 \%)$, total serum IgE of 142,1 IU/mL (normal: below $100 \mathrm{IU} / \mathrm{mL}$ ), specific serum IgE negative for wheat, gluten, and omega-5-gliadin (performed twice). The patient is sensitized to house dust mites Dermatophagoides farinae and Dermatophagoides pteronyssinus. He was advised to wait for 4 to 6 hours after having eaten wheat to initiate aerobic exercises. An epinephrin autoinjector was supplied.

\section{Case 2}

A 41 years-old healthy caucasian female, with a positive family history for atopy, refers that after eating crab and shrimp followed by aerobic exercises she develops severe generalized pruritus and diffuse urticaria, with large coalescent wheals. Emergency intravenous or oral antihistamines relieves her symptoms. She can eat shellfish without difficulties if not exercising afterwards. She also states that while exercising daily, there are no symptoms if she abstains from eating shellfish. Applying positive (histamine) and negative (diluent) controls, prick testing to shrimp, crab, oysters, scallops and clams were negative. She was advised to wait for 4 to 6 hours after having eaten shellfish to initiate aerobic exercises. An epinephrin autoinjector was supplied.

\section{Case 3}

A 39 years-old caucasian female, with rhinitis, bilateral nasal polyps, and a positive family history for atopy, refers that exercising on a treadmill after eating shrimp, she develops laryngeal edema requiring emergency administration of intramuscular epinephrin. Curiously, this does not happen with the other shellfish. She can eat shrimp without difficulties if she does not exercise afterwards. She also states that while exercising daily, there are no symptoms if she abstains from eating shrimp. Laboratory evaluation showed a normal serum tryptase, and twice negative specific serum IgE for shrimp, crab, lobster, oysters and clams. She was advised to wait for 4 to 6 hours after having eaten shrimp to initiate aerobic exercises. An epinephrin autoinjector was supplied.

The most common presentations of exercise-induced anaphylaxis are the food-dependent with IgE sensitization. The non-allergic modalities are uncommon and probably underreported.4,5 Three documented cases of fooddependence without IgE sensitization are described with the following foods: wheat, shellfish and solely to shrimp. The underlying mechanisms of this entity are still unknown. More reported cases in the literature are needed

\section{References}

1. Geller M. Clinical management of exercise-induced anaphylaxis and cholinergic urticaria. J Allergy Clin Immunol Pract. 2020;8:2209-14.

2. Geller M. Diagnostic and therapeutic approach in patients with exercise-induced anaphylaxis. Curr Treat Options Allergy. 2016;3:181-8. 
3. Feldweg AM. Food-dependent exercise-induced anaphylaxis: diagnosis and management in the outpatient setting. J Allergy Clin Immunol Pract. 2017;5:283-8.

4. Feldweg AM. Exercise-induced anaphylaxis. Immunol Allergy Clin North Am. 2015;35:261-75.

5. Romano A, Di Fonso M, Giuffreda F, Papa G, Artesani MC, Viola $M$, et al. Food-dependent exercise-induced anaphylaxis: clinical and laboratory findings in 54 subjects. Int Arch Allergy Immunol. 2001;125:264.
No conflicts of interest declared concerning the publication of this letter.

\section{Mario Geller}

Director, Geller Allergy and Immunology Clinic - Rio de Janeiro, RJ, Brazil.

Lifetime Member of the Academy of Medicine of Rio de Janeiro.

E-mail: drmariogeller@gmail.com 